\title{
O PROCESSO DE ABSORÇÃO DO CONHECIMENTO A PARTIR DA INCERTEZA AMBIENTAL
}

Carlos Ricardo Rossetto ${ }^{1}$

Fernando César Lenzi ${ }^{1}$

Gustavo Behling ${ }^{1}$

Carlos Eduardo Carvalho ${ }^{2}$

\footnotetext{
${ }^{1}$ Universidade do Vale do Itajaí

${ }^{2}$ Universidade do Oeste de Santa Catarina (UNOESC)
} 


\section{O PROCESSO DE ABSORÇÃO DO CONHECIMENTO A PARTIR DA INCERTEZA AMBIENTAL}

\section{Resumo}

Especificamente em um contexto de ambiente de constantes mudanças, o processo de absorver conhecimento proporciona explorar novas oportunidades e responder a um cenário de incertezas. Este artigo objetivou compreender o processo de absorção de conhecimento em uma indústria moveleira de Santa Catarina a partir do modelo proposto por Zahra e George (2002) descrevendo a PACAP e RACAP. Utilizou-se a abordagem qualitativa, com objetivo exploratório-descritivo por meio de estudo de caso. Os dados foram coletados por análise documental e por meio de entrevista semiestruturada. As análises foram desenvolvidas com a técnica de análise de conteúdo com apoio do software Atlas/Ti. A Rudnick desenvolveu habilidades para monitorar as informações do ambiente externo, buscou unir o conhecimento prévio e as experiências para assimilá-las internamente. Teve competência para transformar o conhecimento difundindo com o conhecimento já existente a partir de experiências entre os colaboradores, incentivo a novas ideias e interação interorganizacional.

Palavras-Chave: Capacidade Absortiva. Incerteza. Setor moveleiro. Conhecimento.

\section{Introdução}

Tanto para atender o mercado externo, quanto para atender ao mercado interno, a indústria moveleira enfrenta uma série de desafios, dentre os quais a alta tributação que é agravada pela grande verticalização da produção, a carência de fornecedores especializados em partes e componentes e as crescentes restrições de caráter ambiental ao uso de madeiras de lei. Somase a isso, o cenário já relatado de crise política e econômica e suas nefastas consequências e tem-se um cenário evidente de incertezas e imprevisibilidade sobre a gestão da indústria moveleira.

Assim, os desafios de adaptação para os gestores da indústria moveleira concentram-se nas tentativas de permanecerem atentos às informações do mercado que podem gerar ameaças e oportunidades, cuja informação, unida as habilidades organizacionais, resulta na capacidade de produzir conhecimento. Requer-se que a indústria tenha determinadas competências, cujo desenvolvimento centra-se na maneira como as empresas buscam e exploram as informações. A incerteza produzida pelas mudanças do ambiente evidencia também a necessidade de conhecer o mercado de atuação reunindo o maior número de informações sobre o ambiente externo que podem refletir no crescimento da indústria.

Neste sentido, a busca de informações pode gerar um diferencial competitivo às organizações se exploradas e difundidas para gerar conhecimento. A temática desse trabalho busca compreender os desafios originados da incerteza ambiental na indústria moveleira e que refletem diretamente na tomada de decisão gerencial, especificamente na capacidade de absorver conhecimento (CA) para a organização.

A necessidade em abordar o tema da CA foi apontada na literatura por Versiane et al (2010) que identifica poucos estudos que focam exclusivamente a capacidade absortiva em uma abordagem qualitativa. Poucos estudos empíricos têm abordado a capacidade absortiva sob a natureza multidimensional (D'SOUZA; KULKARNI, 2015; JANSEN, VAN DEN BOSCH, VOLBERDA, 2005; VERSIANI, CRUZ, FERREIRA, GUIMARÃES, 2010), ou seja, não abordam todas as dimensões ao estudar o conceito de capacidade absortiva e, em um contexto de incertezas (LICHTENTHALER, 2009;). 
Pesquisas que abordam o conceito de capacidade absortiva têm se destacado em estudos de empresas em grande porte (FLATTEN, ENGELEN, ZAHRA, BRETTEL, 2011; TODOROVA, DURISIN, 2007). Assim a pesquisa justifica-se quanto o objeto de pesquisa, indústria moveleira de médio porte. Ainda, aponta-se a importância do setor moveleiro para a economia brasileira que é claramente percebido pela sua capacidade de geração de empregos, pela disseminação no território nacional e relevante participação nos números da economia. Além disso, este setor tem passado por periodos de grandes incertezas, o que justifica analisar como ocorre o processo de absorção do conhecimento.

$\mathrm{Na}$ presente pesquisa observa-se o contexto externo como incerteza e o ambiente interno DA Rudinik como o gerador de CA. Importante salientar que toda a pesquisa tem como referência a saída encontrada pela empresa pra sair de uuma crise sem precedentes ocorrida pela flutuação do câmbio. Em função disto, em 2008 a empresa decide investir na linha institucional, suportados pela experiência da parceria com a Boticário, que até este momento ainda era parcial. Essa decisão seria o momento ápice para a sobrevivência da empresa.

A partir dessa aproximação iniciou-se uma nova fase para reposicionar a empresa no mercado. A linha institucional poderia gerar novos rumos para empresa. No entanto, foi necessário buscar conhecimento sobre como atuar nesse segmento. Mesmo a empresa tendo construído um know how de como atender a empresa Boticário, foi preciso conhecer quais as exigências do setor e como atuar nesse segmento. Nesse momento, entra em cena a importância do desenvolvimento de habilidades e capacidades para absorver as informações externas e desenvolver o processo de capacidade absortiva para que o conhecimento culminasse em um resultado satisfatório e rentável.

A incerteza gerada pela turbulência do mercado e a falta de previsão sobre o futuro da taxa de câmbio geraram a necessidade de uma nova estratégia de reação frente ao cenário. Decidir e reagir às incertezas de mercado demandava um novo foco de negócios. $\mathrm{O}$ mercado interno não absorvia mais a produção e a empresa ainda sentia reflexos da rejeição dos clientes. As exportações entraram em crise e muitos clientes do mercado externo buscavam novos fornecedores de móveis.

$\mathrm{Na}$ literatura se observam diversos estudos que têm abordado o fator incerteza ambiental somente como um fator externo, limitando a compreensão sobre a influência do ambiente externo para a construção de capacidades, rotinas e práticas organizacionais que caracterizam o ambiente interno (GARDELIN, ROSSETTO, VERDINELLI, 2011). Autores apontam lacunas de pesquisas que abordam o tema incerteza ambiental, turbulência ambiental e capacidade absortiva (VERSIANE et al.,2010). Por se tratar de um tema relativamente recente (D’SOUZA; KULKARNI, 2015; JENSEN, VAN DEN BOSCH, VOLBERDA, 2005; LANE, KOKA, PATHAK, 2006; ZAHRA, GEORGE, 2002) destaca-se a necessidade de desenvolver estudos empíricos qualitativos que compreendam o processo da capacidade absortiva em períodos de incertezas ambientais.

Neste contexto, o objetivo do artigo é compreender o processo de absorção do conhecimento na empresa Rudnick considerando a PACAP e a RACAP, segundo modelo de Zahra e George (2002), a partir da parceria com a Boticario. Esta pesquisa contribui para o avanço do desenvolvimento dos estudos sobre a compreensão do processo da capacidade absortiva, que são temas de estudos internacionais. Em estudos brasileiros a teoria ainda pode ser desenvolvida aumentando as oportunidades para pesquisas empíricas. As justificativas citadas afirmam que ainda existem gaps teóricos a serem estudados acerca do tema capacidade absortiva, mas que 
ainda é preciso ampliar o campo de pesquisas sobre a teoria sob o contexto de um ambiente de incertezas ambientais.

Outras contribuições desse estudo são propostas para um estudo com abordagem qualitativa de dados, abordando a compreensão das etapas do processo de absorção de conhecimento e a percepção dos gestores sobre a importância do conhecimento como recurso essencial ao crescimento da empresa. Além de propor um modelo para compreender a influência do mercado externo sobre as estratégias organizacionais e sobre a absorção do conhecimento.

No campo empírico, os resultados geram contribuição no entendimento dos gestores sobre a importância de desenvolver competências para absorver conhecimento e sobreviver a um ambiente de incertezas. Também contribui para que os gestores compreender cada etapa do modelo e quão importante é o desenvolvimento de cada dimensão para a eficiência do processo.

\section{Capacidade Absortiva (CA)}

As investigações sobre o tema centraram-se, primeiramente, em estudos sobre pesquisa e desenvolvimento, ampliando o conceito em 1990, com a publicação sobre a perspectiva da capacidade absortiva, aprendizagem e inovação. Esta definição dos autores formou a base para o desenvolvimento de futuras pesquisas e a participação de vários autores sobre o tema.

A primeira atribuição de Cohen e Levinthal $(1989,1990)$ sobre o tema relacionou as atividades de I\&D (inovação e desenvolvimento) na qual a organização desenvolve uma base de conhecimento para compreender e captar as informações externas. Um número significativo de trabalhos incluem pesquisas sobre capacidade absortiva e inovação (KOSTOPOULOS; PAPALEXANDRIS; PAPACHRONI; IOANNOU， 2011LICHTENTHALER，2009; WURYANINGRAT, 2013).

O conceito inicial de capacidade absortiva é definido como a "habilidade da firma em reconhecer o valor de uma nova informação externa, assimilá-la e aplicá-la para fins comerciais" (COHEN; LEVINTHAL, 1990, p. 128). Zahra e George (2002) ampliam o conceito inicial de Cohen e Levinthal (1990) e, de acordo com os autores, trata-se de uma análise multidimensional de competências, formadas por rotinas e processos desenvolvidos por uma estrutura organizacional flexível e dinâmica. A ACAP divide-se em Capacidade Absortiva Potencial (PACAP), composta por aquisição e assimilação; e Capacidade Absortiva Realizada (RACAP), composta por transformação e aplicação (ZAHRA; GEORGE, 2002).

O modelo (Figura 1) desenvolvido por Zahra e George (2002) teve origem da capacidade dinâmica, que utiliza recursos disponíveis na empresa para gerar vantagem competitiva, adaptando o ambiente interno como principal componente para o sucesso do desenvolvimento da capacidade.

Figura 1: Modelo de Capacidade Absortiva de Zahra e George (2002)

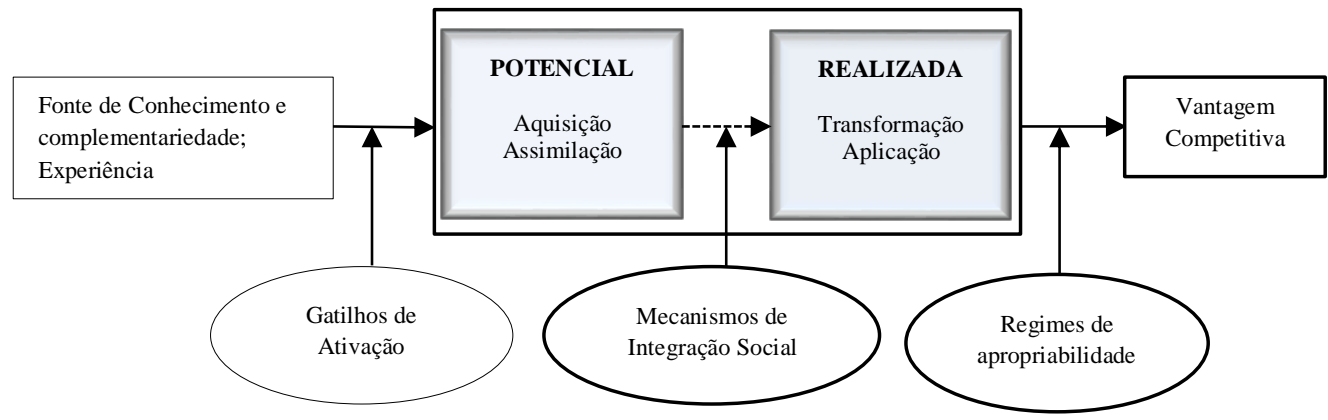

Fonte: Zahra e George (2002) 
As capacidades ou dimensões, objetos deste estudo (PACAP e RACAP), constituintes do modelo de CA de Zahra e George são descritos abaixo.

A primeira etapa Aquisição dá início ao processo da PACAP e se refere-se à capacidade de uma empresa em identificar e adquirir conhecimento gerado externamente, que é fundamental para o seu funcionamento (ZAHRA; GEORGE, 2002). Informações externas são detectadas, capturadas e transmitidas para o interior da empresa para serem selecionadas e interpretadas. O componente Aquisição é definido como "a capacidade de uma empresa para identificar e adquirir conhecimentos gerados externamente que é fundamental para suas operações" (ZAHRA E GEORGE,2002, p. 189). Para Zahra e George (2002), a Assimilação refere-se à capacidade de interpretar e compreender o conhecimento com as estruturas cognitivas existentes na organização e está diretamente relacionado ao seu conhecimento prévio. A informação captada do ambiente externo deve ser transferida para o interior da organização e, em seguida, assimilada e disseminada. "A Assimilação refere-se as rotinas e processos da empresq que permitem analisar, processar, interpretar e compreender as informações obtidas nas fontes externas" (ZAHRA; GEORGE, 2002, p. 189).

A capacidade de Transformação dá início ao processo da RACAP e é considerada a consequência do processo de assimilação (ZAHRA, GEORGE, 2002). Para os autores, a capacidade de Transformação é a interiorização e conversão de novos conhecimentos adquiridos e assimilados, combinando o conhecimento existente com o recém-assimilado e está relacionada com a capacidade de transformar o conhecimento em oportunidades empresariais. Nessa etapa são produzidos conhecimentos e insights que facilitam o conhecimento para novas oportunidades e modificam a maneira de analisar o cenário competitivo.

E finalmente, a capacidade de Aplicação é reconhecida, para Zahra e George (2002), como rotinas que permitam às empresas expandir e potencializar o conhecimento existente e o novo adquirido, a fim de combiná-los e gerar conhecimento valioso para organização (ZAHRA, GEORGE, 2002). É a criação de rotinas para a aplicação dos conhecimentos para uso e implementação que irá levar a novos produtos, sistemas, processos, novas formas organizacionais ou melhorar as habilidades existentes ou mesmo criar novos.

\section{Procedimentos Metodológicos}

O presente estudo atende uma pesquisa de abordagem qualitativa, caracterizada como um estudo de caso de natureza exploratória e descritiva. Em relação aos objetivos, a pesquisa busca explorar como ocorre o processo de capacidade absortiva (PACAP e RACAP) na Móveis Rudinick. A pesquisa tem como objeto de estudo a empresa Rudnick S/A que atua no setor moveleiro localizado no município de São Bento do Sul/SC. Para atingir o objetivo proposto pelo estudo foram entrevistados colaboradores que estiveram na empresa no período identificado pelo membro do conselho como marco de incerteza ambiental ou estão à frente das estratégias de gestão com conhecimento sobre esse momento, conforme Quadro 1.

Os entrevistados foram selecionados fundamentalmente pela acessibilidade $\mathrm{e}$ disponibilidade para responder ao objetivo da pesquisa. O instrumento de coleta de dados foi construído seguindo o modelo proposto nos estudos de Zahra e George (2002) apresentado na Figura 1.

Foi realizado um pré-teste junto a uma empresa de médio porte no ramo metalúrgico localizada no município de Pinhalzinho/SC para identificar possíveis falhas ou inconsistência nas questões. A aplicação foi realizada com três gestores, o primeiro entrevistado responsável pelo departamento de vendas e o segundo responsável pelo setor financeiro, ambos sócio- 
proprietários com mais de 20 anos de atuação na empresa e, o entrevistado responsável pelo departamento de comércio exterior com 6 anos de empresa. Com ele foram feitos ajustes, retirada de questões redundantes e inclusão de outras.

Quadro 1: Relação dos entrevistados

\begin{tabular}{|c|c|c|}
\hline ENTREVISTADO & $\begin{array}{ll}\text { TEMPO } & \text { DE } \\
\text { EMPRESA } & \end{array}$ & CARGO \\
\hline Entrevistado 1 & 45 & Membro Conselho administrativo* \\
\hline Entrevistado 2 & 20 & Diretor Geral \\
\hline Entrevistado 3 & 41 & Gerente de Produção \\
\hline Entrevistado 4 & 24 & Diretor de Design \\
\hline Entrevistado 5 & 27 & Diretor de Produção \\
\hline Entrevistado 6 & 19 & Diretor de Mercado \\
\hline Entrevistado 7 & 7 & Gerente de Vendas \\
\hline
\end{tabular}

Fonte: Elaborado pelos autores.

Para oferecer suporte as análises do conteúdo das transcrições foi utilizadas previamente as categorias de análises que remetem a cada dimensão estudada. Cada categoria construída referese a cada uma das dimensões da PACAP e RACAP do modelo de Zahra e George (2002). A categorização foi estabelecida por grade aberta, ou seja, as categorias definiram-se previamente a partir da base teórica, porém abertas a desenvolver novas categorias caso identificadas no decorrer da pesquisa.

Para aumentar a confiabilidade e validade dos dados utilizou-se o software Atlas/TI para analisar interpretar os dados. O objetivo do software foi auxiliar e gerir os dados para a compreensão, visualização, integração e exploração dos resultados. Com as análises gráficas foi possível visualizar as expressões ditas pelos entrevistados que pertencem a cada categoria, contribuindo para a análise da entrevista e interpretação dos resultados.

\section{Análise e Interpretação dos Resultados \\ 4.1 Capacidade Absortiva}

A capacidade de absorção do conhecimento será analisada a partir do modelo de Zahra e George (2002), o objetivo é compreender como ocorreram as etapas desse processo na empresa no período de incerteza ambiental em que a empresa decide investir na parceria com a indústria de cosméticos e perfumaria Boticário.

\subsubsection{Capacidade Absortiva Potencial \\ Aquisição}

A primeira etapa aquisição dá início ao processo da PACAP e refere-se à capacidade de uma empresa em identificar e adquirir conhecimento gerado externamente, que é fundamental para o seu funcionamento (ZAHRA; GEORGE, 2002). Informações externas são detectadas, capturadas e transmitidas para o interior da empresa para serem selecionadas e interpretadas.

Após concretizar a ideia de investir na linha institucional iniciada com a empresa Boticário a empresa voltou seu olhar para o mercado na busca de informações sobre o setor. A busca de informações destinou-se a melhor responder as expectativas dos clientes, com novos designs sobre os produtos, tendências, novidades em ferramentas, tecnologias e recursos materiais, além do mapeamento da prospecção de novos clientes para acrescentar a linha institucional.

Para o entrevistado 4, responsável da área de inovação, a busca de informação externa foi intensificada na organização. 
A empresa sempre manda uma ou duas pessoas para feiras no exterior, eu fui pra Alemanha e vi que estavam usando muito a cor cobre em 2012 [...].A gente sempre olha o design dos mais famosos, aquele que desenha Armani, também desenha cozinha e se ele colocar puxadores de cobre, bem brilhante e começam a fazer cozinha brilhante parece loucura, mas é moda (ENTREVISTADO 4).

A participação de feiras e eventos no exterior contribuiu para a absorção do novo conhecimento, as tendências sobre o setor trouxe o conhecimento sobre como atuar nesse segmento. A capacidade em prever uma necessidade futura gerou competências para a organização antecipar suas estratégias e criar mecanismos para preparar-se a uma mudança que poderiam ocorrer.

Todorova e Durisin (2007) reafirmam a importância do reconhecimento do valor de uma informação nova para adquiri-la. Os autores alertam sobre a necessidade de aumentar a base de atenção sobre as estruturas cognitivas dos indivíduos e unir as experiências ao conhecimento prévio para gerar a capacidade de avaliar uma informação nova e absorvê-la. Murovac e Prodan (2009) descrevem que as mudanças devem ser bem vindas e vistas sob um contexto positivo para que não sejam distorcidas ou mal interpretadas pelos gestores. As mudanças podem interferir no crescimento da empresa, mas tenderem a ser inovadoras quando indivíduos são motivados a buscar informações que acarretam em melhorias para a organização (VERSIANI et al. 2010).

Para o diretor comercial, a empresa desenvolveu estratégias para buscar informações no ambiente externo e propôs condições para acesso as fontes de conhecimentos que contribuíram para identificar um conhecimento novo. Ao gerar condições a empresa colaborou para se desenvolver novas competências para identificar o conhecimento e uma nova oportunidade.

Nós temos um RADAR com umas duzentas franquias que estamos em processo de abordagem, duzentos clientes diferentes. Em cima desse RADAR estamos contatando a empresa, foi feito um mapeamento, que se consegue em qualquer relatório no site da Francap, se consegue a listagem das empresas e entramos em contato, corpo a corpo, agendamos com o setor de suprimentos, vai até a franquia e apresenta a primeira ideia. (ENTREVISTADO 2).

Para o entrevistado 2, ao implantar o sistema RADAR como ferramenta para absorver o conhecimento, a empresa também esteve atenta a qualquer novidade do mercado. O sistema permitiu monitorar as informações sobre o ambiente e prever possíveis mudanças futuras que poderiam ameaçar o crescimento da empresa, além de trazer benefícios com a implantação de um novo processo. A empresa também disponibilizou um funcionário para atuar no monitoramento do mercado e responsável em absorver as informações úteis para a empresa.

O colaborador responsável por monitorar e assimilar o conhecimento externo é reconhecido como gatekeeper, cuja função é identificar novas informações, interpretar um conhecimento novo e trazer para a organização, acompanhar as mudanças e novas oportunidades (COHEN, LEVINTHAL, 1990).

Para Volberda, Foss e Lyles (2009) o gatekeeper é comparado a um porteiro ou guardião, e acompanha informações técnicas importantes para a empresa, monitora e traduz as informações externas de uma forma compreensível para o grupo. Em ambientes dinâmicos desenvolve importante função de traduzir as informações do ambiente e identificar uma informação valiosa em meio a um ambiente de mudanças.

A Rudnick preocupou-se em desenvolver rotinas que estimulam o monitoramento e aquisição do conhecimento através da implantação do sistema RADAR e um gatekeeper. Tu 
et al. (2006) salienta a importância do monitoramento de conhecimento considerado um mecanismo organizacional que promove a identificação, a aquisição de conhecimento e novas tecnologias de fontes externas que geram um diferencial competitiva em relação a concorrência.

Outro mecanismo identificado pela empresa para buscar conhecimento externo foi gerado a partir do relacionamento com os fornecedores. Conforme relataram o entrevistado 3:

Quando se tem uma dificuldade se reúne e discute como fazer e se contata os fornecedores: $\mathrm{Eu}$ preciso desenvolver uma técnica de curvar uma peça, então eu contato o fornecedor. Qual o material? Qual cor vai combinar? Então eu vou trazer um pessoal especializado. Com o laminado que vai curvar e fazer a curvatura e não quebrar? (ENTREVISTADO 3).

O relacionamento com os fornecedores gerou a capacidade de adquirir um novo conhecimento. Foi através da transferência dos conhecimentos e experiências dos fornecedores que empresa aumentou sua base de conhecimento interno. A busca da informação do que há de melhor no mercado em termos de novidade de recursos está impregnada na cultura da organização, percebe-se que em vários níveis hierárquicos, os setores e colaboradores mantêm o olhar para as informações do ambiente externo.

Zahra e George (2002) alertam que quanto maior for o esforço para absorver o conhecimento, mais rapidamente a empresa vai construir capacidades requeridas para a aquisição. Desenvolver rotinas e processos que auxiliam a aquisição de conhecimento aumentam as condições para a informação ser adquirida e internalizada

\section{Assimilação}

A assimilação refere-se a rotinas e processos da empresa que permitem analisar, processar, interpretar e compreender a informação obtida a partir de fontes externas (ZAHRA, GEORGE, 2002, p. 189).

Na percepção dos gestores, os desafios e o relacionamento com a empresa Boticário geraram a necessidade de uma cultura de aprendizagem organizacional. Foram unindo experiências, vivências e conhecimentos individuais de pessoas especializadas. A experiência em atuar nesse segmento foi sendo construída com disseminação das informações adquiridas externamente. $\mathrm{O}$ entrevistado 6 relata que o aprendizado está associado na construção e reprodução do conhecimento, resultado da absorção de uma informação externa e disseminada internamente para gerar conhecimento novo.

[...] o que a Boticário mandar a gente aprende, aprende fazendo e a gente aprende, a gente cresce. Esse aprendizado é espalhado pra toda empresa, o pintor sabe como fazer, o setor de produção aprende, a engenharia aprende, inovação aprende, marketing aprende (ENTREVISTADO 6).

Ao ser questionado sobre a parceria com a Boticário e a empresa, o entrevistado 6 relata que a além do desafio em atender a demanda em um produto diferente da qual a empresa estava produzindo, a Boticário exigia excelência na entrega dos produtos e isso exigiu a participação de todos, da interação e da união de todos os funcionários para que com ideias e sugestões pudessem criar a solução que a empresa esperava. Os gestores ainda relatam que a disseminação da informação para toda a empresa também contribuiu para evitar desperdícios e falhas nos processos.

A informação entrou e foi disseminada para toda a empresa, então, qualquer problema que aconteça a gente acaba reunindo todos os envolvidos no processo e fala: olha gente estamos falhando nesse aspecto com o cliente, então reúne e interage 
com toda a empresa, todo pessoal de engenharia e produção [...] a própria empresa se movimenta diferente dentro da empresa para isso (ENTREVISTADO 2).

Quando a boticário viu que nós conseguimos fazer aquele primeiro projeto e o segundo que saiu melhor que o primeiro, você coloca todo esse conhecimento, todas as pessoas, todas as experiências já feitas, e isso foi começando a ganhar corpo e deu certo (ENTREVISTADO 6)

A flexibilidade na troca de conhecimento entre a Rudnick e a Boticário ocorreu de forma dinâmica, promovendo maior compreensão e interpretação para o entendimento da informação nova, e isto corrobora com Zahra e George (2002) que afirmavam que a flexibilidade e a troca de experiências dos indivíduos envolvidos permitem a compreensão e entendimento da informação gerada no exterior da empresa. Ao ser questionado sobre a troca de experiências interorganizacional o entrevistado 2 confirma a necessidade de manter a aproximação para gerar a troca de conhecimentos.

[...] essa dinâmica e a interação com as pessoas lá dentro é um crescimento muito forte para todas as áreas da empresa, começa na engenharia trocando ideias entre o pessoal deles lá. A troca de informação com a empresa é muito forte e muito dinâmica, o Alex ta em contato direto com eles na linha de negócios então a comunicação é quase que diária com o pessoal as ideias vão surgindo (ENTREVISTADO 2).

A troca de conhecimento e comunicação interna foram pontos positivos que contribuíram para a parceria com a Boticário. A Rudnick sempre zelou pelo relacionamento com a empresa para que a troca de informações pudessem oportunizar um novo aprendizado e acabou gerando um novo conhecimento para a empresam conforme o entrevistado 4. A comunicação interna foi um mecanismo inserido na cultura da Rudnick e permanece até hoje.

Todo dia tem uma reunião das células, o planejamento. $O$ pessoal se reúne para planejar o dia seguinte, não é o monitor é o pessoal da fabrica, a gente já conseguiu trazer não só o monitor mas o nível da célula, o nível da furadeira, o nível da coladeira, o nível da administração, o nível da embalagem, eles vão planejar o dia seguinte, em função da embalagem, o que eu tenho que fazer para o dia seguinte? (ENTREVISTADO 4).

Nas pesquisas sobre o tema, Cohen e Levinthal (1990) descrevem os principais mecanismos organizacional que influenciam o nível de capacidade absortiva na empresa e são identificadas pela transferência de conhecimento entre e dentro as unidades, a estrutura de comunicação entre o ambiente externo e da empresa e o nível de relacionamento inter pessoal.

$\mathrm{O}$ entrevistado 3 foi questionado sobre a troca de conhecimento entre funcionários e interdepartamental e sobre a importância dessa integração para a disseminação da informação entre toda empresa.

[...] o aprendizado absorvido com essa parceria com a Boticário se dissipou para todas as nossas linhas, da maneira em interagir com os fornecedores, a questão de sempre haver a melhoria continua [...]. Então existe uma interação muito grande com a Boticário. Eles vem pra cá, ou o pessoal vai pra lá trocar ideias ou traz o conhecimento pra cá, então isso acontece e é forte (ENTREVISTADO 3)

Um alto nível de profissionalização é necessário para que o funcionário desenvolva competências e habilidades adquirir o conhecimento para explorá-lo de forma eficiente, além de investimentos em P\&D que estimula a construir um olhar inovador sobre o novo conhecimento. Para o entrevistado 1, essa é uma prioridade da administração da empresa 
"Sim a empresa sempre vem incentivando a capacitação com cursos e oferece subsídio para os funcionários que desejam fazer algum curso que interessa a empresa" (ENTREVISTADO 1).

Essa integração entre departamentos e indivíduos, abordados nos estudos de Liao, Welsch e Stoica (2003), emplica o sucesso da assimilação a partir dos fluxos de conhecimentos e partilhas que garantem que o conhecimento atinja as pessoas interessadas. Os estudos de Zahra e George (2002) afirmam que as empresas não podem aplicar o conhecimento externo sem antes não ter adquirido e internalizado em seus processos organizacionais. Para Vega-Jurado, GutierrezGracia e Fernandez-de-Lucio (2008) em ambientes altamente dinâmicos as etapas da PACAP facilitam o processo de adaptação às mudanças destes ambientes para se adaptarem às mudanças, aplicar novos caminhos e remodelar sua base de conhecimento.

\subsubsection{Capacidade Absortiva Realizada}

A RACAP é a dimensão da capacidade absortiva que compreende as etapas de transformação e aplicação.

\section{Transformação}

A transformação do conhecimento está diretamente ligada ao resultado da assimilação da informação, passo subsequente da internalização que desperta um novo aprendizado e dará origem a um novo conhecimento. É o processo de bissociação do conhecimento novo, interpretado, assimilado e combinado com o conhecimento já existente na organização que resulta em um novo esquema de aprendizado, unindo o conhecimento adquirido externamente com o conhecimento prévio (D’SOUZA; KULKARNI, 2015; JANSEN, VAN DEN BOSCH, VOLBERDA 2005; TODOROVA, DURISIN 2007).

A parceria com a empresa proporcionou a transformação do conhecimento ao longo dos anos, os desafios gerados pela parceria e a exigência da Boticário na produção do que há de moderno e atual demandavam uma estrutura de gestão que gerasse a proatividade em compartilhar conhecimento e experiências intensamente e buscar constantemente novo conhecimento no mercado externo.

A integração entre os funcionários da Rudnick e o Boticário provocou um estímulo a um novo aprendizado que foi se disseminando na cultura da empresa. Na dinâmica de desenvolver o aprendizado na Rudnick e responder aos desafios que a empresa gerava tornou a estrutura organizacional flexível e a necessidade da participação de todos para uma construção em conjunto do conhecimento. $\mathrm{O}$ entrevistado 5 relata que para produzir Boticário, desde o início do relacionamento ao receber um projeto novo, a empresa se organizava internamente e disseminava a informação para todas as áreas para seja montada uma estrutura com a interação de todos.

Se eu vou produzir isso dentro da linha projetado, então eu vou trazer toda a maestria daquela linha e eles vão apresentar o projeto e já vão surgir os pontos críticos, como vamos fazer isso? Aquele móvel, aquela curva, aquele brilho. Várias dúvidas vão surgindo e já dá um direcionamento com o estilo. Então já saem com uma ideia (ENTREVISTADO 5).

O gestor também salienta que a cooperação e a conectividade dos funcionários resultam diretamente na qualidade final do produto e por isso é priorizado em todos os processos na empresa. Ele confirma que no momento da execução dos projetos todos os envolvidos permanecem unidos a cada etapa do processo, pois a discussão e a interação de todos 
permanecerão até o processo final. $\mathrm{O}$ entrevistado 2 relata como a interação de todos foi importante para a conclusão do projeto para a construção do conhecimento

[...] quando ele vai fabricar cada móvel, ele vai de novo trazer para uma discussão, as mesmas pessoas que estão participando, a engenharia, o marceneiro, o condutor da usinagem, o monitor do pré corte, o monitor da embalagem e todo mundo já ta pensando como é que eu vou furar, como é que vou cortar, como é que vou usinar. Então já começamos no projeto uma união de discussões. (ENTREVISTADO 2).

Para Jansen, Van Den Bosch (2005) esse envolvimento de funcionários de diversas áreas promovem a integração de conhecimentos e fomenta o compartilhamento de valores e interpretações o que favorece a compreensão do novo conhecimento. $\mathrm{O}$ entrevistado 3 relata que a empresa buscou filosofias estrangeiras para somar aos processos internos da empresa que contribuíram para a aprendizagem organizacional. Nesse sentido, o entrevistado salienta a importância da participação de todos no compartilhamento do novo conhecimento para que seja criada uma nova percepção sobre determinada situação que origine um novo resultado.

A filosofia Toyota envolve muitas pessoas no sentido de poder dar sugestões. Eu gosto muito dessa filosofia, também a filosofia Lean, a gente busca se espelhar na filosofia Lean e trabalhar dessa forma, aquela parceria, cooperação, interação entre as pessoas também é espelhado nessa filosofia Lean (ENTREVISTADO 3).

Os gestores recordaram o aprendizado e as competências desenvolvidas com a parceria com o Boticário e relataram um evento ocorrido que mudou os processos cognitivos internos e deu origem a uma nova cultura organizacional de aprendizado que se dissipou por toda a empresa. Os desafios despertaram a necessidades dos funcionários em buscar novos conhecimentos e não limitar-se somente no conhecimento já existente conforme relata o entrevistado 2.

Fazer uma gaveta para um móvel da empresa a Boticário, eles exigem tudo em 45 graus mas não pode aparecer a emenda, então como que se faz para montar um móvel a 45 graus na ponta não aparecer emenda? A gente sabe que a chapa trabalha, vai ter a própria oscilação da temperatura. $O$ pessoal aqui quebrando a cabeça e chegou numa maneira de fazer esse produto não aparecer a emenda e pode ser disseminado para todos os produtos dentro da empresa. [...] O pessoal da engenharia falaram: vamos estudar o projeto e ver uma maneira que não apareça a emenda, e chegaram na fórmula de fazer a gaveta (ENTREVISTADO 2).

O gestor relata que foi necessário quebrar alguns paradigmas de pensamentos pré-existentes e desconstruir uma mentalidade já impregnada na cultura da empresa, classificada como bissociação do conhecimento. Nesse sentido Todorova e Durisin (2007) defende o processo de bissociação para desenvolver um novo esquema cognitivo de percepção que altera os modelos já existentes sobre o entendimento sobre determinada situação, ou seja, se desenvolva uma nova compreensão sobre a realidade já existente. Para os autores isso só será possível excluindo ou somando conhecimentos ou pela interpretação de uma maneira diferente. Questionado sobre quais as mudanças ocorreram internamente com o relacionamento com a Boticário, o entrevistado 7 menciona a principal mudança ocorrida na empresa.

Quebrar paradigmas é o principal [...] O segundo ponto foi o fato de incorporar e resolver problemas para os clientes, eles queriam uma mesa, desse tamanho, dessa altura, dessa largura, e como faz pra ficar em pé? Aí começou a ter mais demanda da engenharia, analisar as estruturas, buscar soluções, buscar materiais no mercado, ferragens, o que o cliente demandou de soluções impulsionou a Rudnick correr atrás dessas soluções, ate então tudo era impossível (ENTREVISTADO 7). 
Um novo modelo de aprendizagem foi incorporado nos modelos mentais dos funcionários a partir desses desafios que foram difundidos para toda a organização e os resultados obtidos também foram se alastrando nas demais linhas.

Agora tá muito bem difundido graças a Boticário que queria isso daquela forma e nós fomos trabalhando, trabalhando, trabalhando e nós conseguimos fazer daquela forma e conseguimos fazer bem e isso hoje migrou bastante para outros produtos e outros produtos de outros clientes (ENTREVISTADO 3).

O envolvimento de todos sempre foi uma cultura impregnada na organização gerando a construção do conhecimento que está armazenada na memória organizacional. O entrevistado 3 expõe as ações desenvolvidas para a transformação do conhecimento.

Transformar essa ideia na pratica é tentativa e erro porque é um desafio, a informação tá aí agora pôr na prática é transformar e isso é uma coisa que se tiver algumas pessoas na equipe que acompanham é muito importante. É trabalhoso porque precisa da interação de todo mundo e depois da quinta, sexta, sétima vez as pessoas ficam com vontade de desistir e isso é um aprendizado legal. Vamos tentar assim, daí começa dar certo e o pessoal se anima e isso é muito lega de fazer (ENTREVISTADO 3).

\section{Aplicação}

Nos estudos de Zahra e George (2002) essa etapa dá origem a implementação de novos produtos, sistemas, processos e formas organizacionais que trazem melhorias para a gestão organizacional. $\mathrm{O}$ entrevistado 3 relata que a parceria com a Boticário permitiu que o conhecimento já desenvolvido para atendê-los pudesse se expandir para as demais linhas. Esse novo conhecimento gerou novos processos produtivos e novos produtos resultado da construção de protótipos, conforme cita o entrevistado a seguir.

A Boticário abriu varias portas [...] o conceito de trabalhar com curvas, fazer coisas arredondadas, não um canto poque nós já fazíamos assim. Mas curvas no sentindo assim, o pé de mesa, por exemplo, curvado assim, coisas muito mais complexas que nós nem pensávamos em fazer (ENTREVISTADO 3).

O entrevistado 4, responsável pelo departamento de design e inovação, também lembra que novas melhorias foram surgindo com a implantação de novos processos no setor produtivo. Além de proporcionar melhorias produtivas, os processos resultaram em qualidade do produto.

Nós inserimos muitos processos novos que melhorou muito [...], por exemplo, a célula das gavetas, tem uma célula que só faz gaveta, foi padronizado gavetas, que faz gaveta, fura, tudo, sempre da mesma altura. Ela começa e termina ali, já vai pra caixa, antes passava em toda fabrica, todo mundo mexia, e ali faz e já põe na caixa, e acabou (ENTREVISTADO 4).

O entrevistado 5 relata que a cultura de inovação está impregnada na cultura organizacional, sendo um produto produzido a cada dia e novos testes pilotos são desenvolvidos para o desenvolvimento de novos produtos. $\mathrm{O}$ entrevistado ainda recorda que a cultura de incentivo a inovação iniciou com a parceria com a Boticário. A engenharia fazia o contato entre as empresas e tinha a necessidade de propor novas ideias e novos produtos, além de inovar constantemente para sempre oferecer o que havia de mais moderno.

A engenharia, o cuidador do projeto que fazia um contato direto, um elo diretor com a Boticário [...] Você faz um protótipo vai lá, você senta e muda. Volta pra cá, então o elo de comunicação é a engenharia (ENTREVISTADO 5). 
O entrevistado 3 relaciona uma nova ideia com o objetivo de explorá-la, trabalhando para que uma nova ideia seja trabalhada para gerar resultados. $O$ entrevistado disse que a empresa aplica o conhecimento para criar novos produtos, como o exemplo da mesa de centro.

Então, nesse sentido a gente trabalha e explora bastante. A ideia se explora através de um produto novo, de um protótipo ou até mesmo de uma melhoria, a gente faz muito isso. A gente faz uma mesa de centro que deu um trabalho pra engenharia e foi justamente fruto desse negocio (ENTREVISTADO 3).

O entrevistado 4 também recorda que após a Boticário, novos desafios foram surgindo e a empresa foi aplicando o conhecimento que havia adquirido ao longo do tempo. A aplicação do conhecimento também resultou na conquista de novos mercados e a expansão dos negócios. $\mathrm{O}$ entrevistado 4 recorda do primeiro contato com a franquia Cacau Show, quando as empresas firmaram a parceria de negócio. A Cacau Show apresentou um projeto para fabricação de uma árvore de chocolate que imita a árvore do cacau. Ele lembra que no primeiro momento essa ideia seria impossível, mas por meio da aplicação do conhecimento adquirido e construído internamente, pode-se criar esse novo produto. Esse exemplo resultou na inovação de produtos e a conquista de novo mercado.

O entrevistado 7 relata que a utilização do conhecimento adquirido internamente destina-se a aplicação para fins comerciais, esse conhecimento proporciona a empresa uma vantagem competitiva em relação as concorrentes em que a empresa tem o foco na vende de uma solução que vai além de um produto. $\mathrm{O}$ entrevistado 5 diz que a empresa aplicou o conhecimento adquirido com o aumento das vendas e gerando novas oportunidades de negócios, criando processos e rotinas que foram desenvolvidas para atender a linha institucional. Conforme relatam os gestores, a disseminação desse conhecimento gerou novas competências internamente e tiveram reflexo positivo no mercado externo.

A gente entende o projeto do cliente, entende o que ele quer, o que o cliente busca em nós, é uma consultoria.. é possível fazer quanto vc acha que vou gastar? O que dá pra fazer? A gente faz consultoria e no final entrega o produto. Mas a primeira aproximação com o cliente é transferir o conhecimento que a gente tem, se faz dessa maneira ou não faz, dessa curvatura ou não faz, dessa material ou outro, faz metal, usa led ou se não usa. É isso que a gente vende hoje (ENTREVISTADO 7).

Temos diversos processos novos que acabam vindo com essa linha, são processos novos. Por exemplo, o 45 graus, hoje temos móveis dentro da fábrica que ocasionou da institucional para a convencional. É uma competência que tivemos que trazer e que já está se disseminando nas demais linhas, que é um diferencial no mercado, são poucos que conseguem fazer. Então essa competência se criou dentro de casa. (ENTREVISTADO 5).

O entrevistado 4 recorda um fato em que o conhecimento foi transformado internamente e aplicada mas continua gerando resultados até hoje. Na busca em interagir com as novidades e lançamentos de insumos no mercado a empresa identificou um espelho de acrílico que imita um espelho de vidro, mas com maior custo $\mathrm{x}$ beneficio na qual não quebra, é mais fácil manusear e imita perfeitamente o original.

[...] espelho, nós nunca pensamos em utilizar, a gente nunca imaginava que tinha, quer dizer eu nem imagina que existia espelho de acrílico.. [...] então a gente aprendeu a trabalhar com acrílico, até uma empresa veio e se instalou aqui porque não tinha empresa de acrílico, dai veio por causa do institucional de tanto a gente pedir.. a pessoa veio e montou.. e isso foi resultado da linha institucional e a Boticário. $\mathbf{O}$ acrílico foi resultado da produção pra Boticário e da linha institucional e hoje nós utilizamos em outras linhas e o resultado é surpreendente (ENTREVISTADO 4). 
Esse fato nos revelou a capacidade da empresa em absorver um conhecimento externo, assimilar e transformar em um conhecimento útil que gerou um resultado para a organização. Em um primeiro momento a informação de utilizar acrílico para fabricar espelho não seria aplicável, mesmo que a empresa reconhecesse o valor dessa informação não era possível aplicar para a realidade na percepção da empresa. É a partir de um novo modelo de aprendizado que a empresa desenvolveu e provoca a quebra de paradigma do que estava sendo feito para um olhar novo que permitiu unir o conhecimento prévio com o novo conhecimento.

Os entrevistados 2 e 4 explicam que o relacionamento com a empresa Boticário deu suporte a Rudnick aplicar o conhecimento e aplica-lo comercialmente analisando a configuração da loja e a interação do cliente em acessar os produtos disponíveis, a discussão permite avaliar se o cliente está interagindo com os produtos na loja ou criando o receio de gerar compra. Dessa maneira a empresa aplica o conhecimento construído na empresa e transfere a Boticário para gerar resultado sobre as vendas, é a aplicação do conhecimento a partir da parceria com a Boticário que gera efeitos positivos sobre as vendas e alavanca novas oportunidades para a Rudnick.

\begin{abstract}
Essa discussão acontece e nós começamos a nos perguntar: se nós mudássemos o módulo de x para y, não vai incentivar o cliente a acessar mais o produto? Essa discussão que a gente faz, são encontros da Rudnick com a Boticário que vamos tentar achar meio e solução para esse problema (ENTREVISTADO 2).

Vou dar um exemplo, nós vamos lançar a cor que nós chamamos de cor natural, então estamos fazendo um monte de testes, estamos trabalhando com a madeira jequitibá então tivemos que ir atrás da madeira [...], a gente viu isso no exterior e ah, vai cair no Brasil! Igual o que aconteceu com a cor branco of White é o branco gelo que não é mais branco igual folha é um branco acinzentado. Nós fomos no exterior vimos isso e já se antecipamos. (ENTREVISTADO 4).
\end{abstract}

Com o exemplo do entrevistado 4 pode-se verificar a cultura de inovação desenvolvida na empresa e um olhar voltado ao mercado externo. Aplicar as novas ideias e o desenvolvimento de novos produtos foi inserido em toda a empresa.

A partir das análises realizadas, resultado das entrevistas, foram identificadas evidências que conduziram a Rudinik a desenvolver o processo de absorção do conhecimento, refletido nas capacidades que compõem a PACAP e a RACAP. Estas evidencias estão descritas na Figura 2.

\title{
5. Considerações Finais
}

Esta pesquisa teve por objetivo compreender o processo de absorção do conhecimento na empresa Rudnick em período de incerteza ambiental. Um destaque importante concentra-se na participação da empresa Boticário no período identificado como incerteza, atuando como fonte de conhecimento e parceira na troca de conhecimentos para a decisão da Rudnick em atuar no mercado institucional.

Entre os meios de aquisição de informação identificadas na Rudnick, destacou-se pela participação de feiras, workshops, criação de redes pessoais, na busca por especialistas na área, como o exemplo da contratação de um profissional da área de materiais networking e no desenvolvimento de pesquisas de mercado. Também foi identificado esforços que objetivam o monitoramento do ambiente e a atuação de gatekeepers para acompanhar as mudanças e tendências do mercado. Verifica-se a ação da empresa em investir na implantação do sistema RADAR, selecionando um colaborador exclusivo para monitorar o ambiente e acompanhar as possíveis mudanças no mercado. É possível contemplar a atuação proativa da empresa em 
monitorar constantemente o ambiente e buscar novas informações que incorporam ao conhecimento já existente.

A etapa de assimilação também foi reflexo da cultura de comunicação flexível, a troca de informações internamente e entre as empresas. A gama de informações internalizadas com a parceria, as experiências adquiridas e o conhecimento prévio sustentaram a assimilação das informações adquiridas externamente. Também foi constatada a realização de reuniões periódicas, a integração e a troca de conhecimento individual entre funcionários.

Para a dimensão transformação foram identificadas evidências sobre o compartilhamento de experiências práticas de maneira formal e informal, incentivos ao desenvolvimento de novas ideias, os investimentos em cursos e treinamento aos funcionários. Pode-se compreender nas entrevistas dos gestores a conectividade e interação entre os colaboradores como uma característica destacada na empresa, o incentivo a troca de conhecimentos e a construção do novo conhecimento com a participação de todos. A bissociação entre o conhecimento existente com o novo conhecimento provocou a transformação do conhecimento em resultados evidentes, pôde ser transformado e difundido para as demais linhas de produção, consequência da PACAP, que transforma e aplica o conhecimento para gerar resultados.

A aplicação do conhecimento foi identificada e praticada na empresa no incentivo em P\&D, na criação de protótipos e incentivos a inovação. A construção de protótipos e testes piloto condiz a uma cultura de inovação na Rudnick. Outro fato relevante sobre a etapa de aplicação foi à necessidade de implantação de um departamento de engenharia na empresa. No primeiro momento o departamento foi desenvolvido com o objetivo de atender às necessidades da Boticário. Como resultado do processo da capacidade absortiva a empresa se manteve no mercado e resistiu ao período de incerteza ambiental, reagiu a crise cambial e a forte ação da concorrência. Como resultado do desenvolvimento de competências para gerir informações e absorver conhecimento a Rudnick sobrevive ao momento de turbulência no setor e decide investir na linha institucional.

A limitação do presente estudo está em utilizar uma única empresa para analisar o modelo proposto. A utilização de um estudo multicasos poderia gerar um estudo comparativo para compreender como ocorreu o processo de absorção do conhecimento entre as empresas do setor, em um mesmo período de incerteza ambiental.

Como sugestão a futuras pesquisas recomenda-se a identificação de maior número de incertezas para verificar como o ocorreu o processo de CA em diversos períodos de incerteza ambiental. Esse estudo pode ser reaplicado em outros setores, como empresas de serviços e indústrias de outros ramos de atividades. Sugere-se a utilização de outros modelos propostos por demais autores, como o modelo de Todorova e Durisin (2007) que desenvolvem reconceitualizações e contribuem para o modelo de Zahra e George (2002). Seria oportuno a utilização dos procedimentos metodológicos desenvolvidos nesse estudo em futuras pesquisas, contribuindo para a validade do método utilizado.

\section{Referências}

BARDIN, L. L'analyse de contenu. Paris: Presses universitaires de France, 2009.

COHEN, W. M.; LEVINTHAL, D. A. Innovation and learning: the two faces of R \& D. The economic journal, p. 569-596, 1989.

COHEN, W. M.; LEVINTHAL D. A. Absorptive capacity: a new perspective on learning and innovation. Administrative science quarterly: 128-152. 1990. 
D’SOUZA, D.E.; KULKARNI, S.S. A framework and model for absorptive capacity in a dynamic multi-firm environment. International Journal Production Economics. 167. 50 62. 2015.

FLATTEN, T. C.; ENGELEN, A.; ZAHRA, S. A.; BRETTEL, M. A measure of absorptive capacity: Scale development and validation. European Management Journal, 29(2), 98116, 2011.

GARDELIN, J. P.; ROSSETTO, C. R.; VERDINELLI, M. A. A percepção da incerteza ambiental e do comportamento estratégico no processo de formulação de estratégias em pequenas empresas.Encontro de Estudos em Estratégia, Anais... Porto Alegre, 2011. JANSEN, J. JP; VAN DEN BOSCH, F. AJ; VOLBERDA, H. W. Managing potential and realized absorptive capacity: how do organizational antecedents matter?. Academy of Management Journal, v. 48, n. 6, p. 999-1015, 2005.

KOSTOPOULOS, K.; PAPALEXANDRIS, A.; PAPACHRONI, M.; IOANNOU, G. Absorptive capacity, innovation, and financial performance. Journal of Business Research, 64(12), 1335-1343. 2011.

LANE, P. J.; KOKA, B. R.; PATHAK, S. The reification of absorptive capacity: A critical review and rejuvenation of the construct. Academy of management review 31.4: 833-863, 2006.

LIAO, J.; WELSCH, H.; STOICA, M. Organizational absorptive capacity and responsiveness: an empirical investigation of growth-oriented SMEs. Entrepreneurship Theory and practice, v. 28, n. 1, p. 63-85, 2003.

LICHTENTHALER, U. Absorptive capacity, environmental turbulence, and the complementarity of organizational learning processes. Academy of Management Journal 52.4, 822-846, 2009.

MUROVEC, N.; PRODAN, I. Absorptive capacity, its determinants, and influence on innovation output: Cross-cultural validation of the structural model. Technovation, v. 29, n. 12, p. 859-872, 2009.

TODOROVA, G.; DURISIN, B. Absorptive capacity: valuing a reconceptualization. Academy of management Review, v. 32, n. 3, p. 774-786, 2007. TU, Z.; WANG, L.; ARBEITMAN, M.N.; CHEN, T.; SUN, F. (2006) An integrative approach for causal gene identification and gene regulatory pathway inference.

Bioinformatics, 22(14):489-96.

VEGA-JURADO, J.; GRACIA-GUTIÉRREZ, A.; FERNÁNDES-DE-LUCIO, I. Analyzing the determinants of firm's absorptive capacity: beyond R\&D. R\&D Management, v. 38, n. 4, p. 392-405, 2008.

VERSIANI, A., CRUZ, M., FERREIRA, M., \& GUIMARÃES, L. Mensuração da

Capacidade Absortiva: até que ponto a literatura avançou. Encontro Nacional da Associação

Nacional De Pós-Graduação e Pesquisa em Administração. Vol. 34. 2010

VOLBERDA, H.; FOSS, N.; LYLES, M. Absorbing the Concept of Absorptive Capacity:

How to Realize ItsPotencial in The Organizational Field. Organizational Science, 21, 931951, 2010.

WURYANINGRAT, N. F. KNOWLEDGE SHARING, Absorptive Capacity and Innovation Capabilities: An Empirical Study on Small and Medium Enterprises in North Sulawesi, Indonesia Gadjah Mada International Journal of Business. Vol. 15.1. 2013. ZAHRA, S. A.; GEORGE, G. Absorptive capacity: A review, reconceptualization, and extension. Academy of management review 27.2: 185-203. 2002. 


\section{XIEGEPE}

\section{ANAIS DO CONGRESSO}

ISSN: 2525-7838 | BELO HORIZONTE/MG

EMPREENDEDORISMO E PEQUENOS NEGÓCIOS - DESAFIOS, OPORTUNIDADES E CONTRIBUIC̣ÕES PARA O DESENVOLVIMENTO TERRITORIAL SUSTENTÁVEL

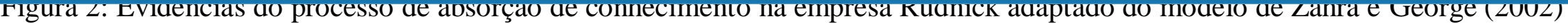

\begin{tabular}{|c|c|c|c|}
\hline \multicolumn{2}{|c|}{ CAPACIDADE ABSORTIVA POTENCIAL } & \multicolumn{2}{|c|}{ CAPACIDADE ABSORTIVA REALIZADA } \\
\hline $\begin{array}{l}\text { AQUISIÇão } \\
\text { • Parceria com outras } \\
\text { empresas; } \\
\text { - Participação em feiras e } \\
\text { eventos internacionais; } \\
\text { - Parceria com fornecedor; } \\
\text { - Relacionamento com } \\
\text { empresas especializadas em } \\
\text { materiais para buscar o que há } \\
\text { de novidades no mercado; } \\
\text { - Implantação de sistema Radar } \\
\text { para monitorar o mercado; } \\
\text { •Criação de departamento de } \\
\text { engenharia para incentivo a } \\
\text { P\&D; } \\
\text { •Colaborador responsável para } \\
\text { acompanhar o mercado } \\
\text { (gatekeeper); }\end{array}$ & $\begin{array}{l}\text { ASSIMILAÇão } \\
\text { - Empresa estimula troca de } \\
\text { informação entre } \\
\text { colaboradores e entre equipes; } \\
\text { - Bom relacionamento que } \\
\text { favorece a troca de } \\
\text { conhecimento entre a Rudnick } \\
\text { e Boticário; } \\
\text { - Troca de conhecimento entre } \\
\text { funcionários na solução de } \\
\text { problemas; } \\
\text { - Participação de todos os } \\
\text { envolvidos em cada processo; } \\
\text { - Rápido fluxo de informação } \\
\text { na empresa; } \\
\text { - Reunião diária do setor com } \\
\text { todos os envolvidos da célula. }\end{array}$ & $\begin{array}{l}\text { TRANSFORMAÇão } \\
\text {-Equipe tem confiança uns } \\
\text { nos outros; } \\
\text { - Incentivo a participação } \\
\text { em cursos para capacitação } \\
\text { dos funcionários; } \\
\text { - Bissociação } \\
\text { - Incentivo a novas ideias; } \\
\text { - Treinamento dos } \\
\text { funcionários por meio do } \\
\text { manual de instrução; } \\
\text { - Interação constante entre } \\
\text { engenharia e departamento } \\
\text { de design; } \\
\text { - Cooperação entre } \\
\text { colaboradores para a } \\
\text { construção do } \\
\text { conhecimento; } \\
\text { - Interação e } \\
\text { compartillhamento de } \\
\text { conhecimento entre todos os } \\
\text { setores. }\end{array}$ & $\begin{array}{l}\text { APLICAÇão } \\
\text { - Incentivo a criação de } \\
\text { protótipos; } \\
\text { - Empresa realiza teste piloto } \\
\text { para desenvolver novos } \\
\text { produtos. } \\
\text { - Desenvolvimento de um } \\
\text { produto novo por dia; } \\
\text { - Criação departamento } \\
\text { exclusivo de inovação; } \\
\text { - Inovação em rotinas e } \\
\text { processos produtivos que } \\
\text { visam eficiência; } \\
\text { - Conquista de novos } \\
\text { mercados; }\end{array}$ \\
\hline
\end{tabular}

Fonte: Elaborado pelosautores

DOI: $10.14211 / \mathrm{xi}$-egepe-118076

SKen

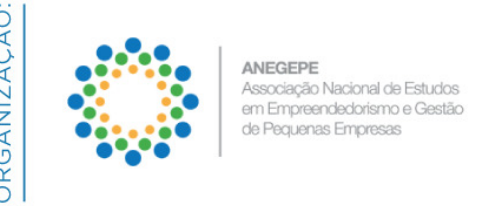

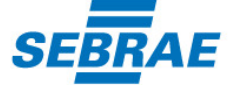

